\title{
ON QUANTITATIVE HISTO- AND CYTOCHEMISTRY AND GENERAL REFLECTIONS*
}

by

\author{
DAVID GLICK
}

Cancer Biology Research Laboratory, Department of Radiology, Stanford University School of Medicine, Stanford, California 94305

\begin{abstract}
Keywords: Histochemistry, cytochemistry, quantitative histo-cytochemical development, microbioanalytical techniques
\end{abstract}

It is obvious that the understanding of any fundamental mechanism of life requires an understanding of the chemistry and function of structural units of living matter. The basis of this understanding might be stated to be the merging of localization and measurement of biological substances and activities to reveal the chemistry and function of the structural units in tissues, cells and their component parts, in both normal and altered states. This is the goal of quantitative histo- and cytochemistry.

Historically, the quantitative aspects of this field, though critically magnifying the value of the morphological information, has received less attention than the chemical localization per se, for the reason that most of those who entered the field had backgrounds and interests principally in the morphological sciences. This has been changing at an accelerated rate with the broader training of the scientists and with the growing maturity and sophistication of the field.

The enhancement of the advance of histo- and cytochemistry through measurement has follo- wed various paths along both chemical and physical lines. However, the advance has been dictated to a great degree by the instrumental and methodological means available. Even though all advance must originate in concept, to bring the concept to reality the limiting factor most often is the technical means of proceeding. Concepts tend to run far ahead of what can be realized at the time. Given the concept, as ClaUde BERNARD said over a hundred years ago, "In experimental science all progress is measured by improvement in the means of investigation". Although methods and techniques are only tools for acquiring knowledge, it cannot be denied that the tools very often determine not only how, but if, the testing and application of concepts can proceed.

The direct chemical approach in the field was the microanalytical one given special impetus by LINDERSTRØM-LANG and HOLTER starting in 1931 (9). Accounts of the techniques and applications developed by them and their associates, as well as of those who subsequently extended

\footnotetext{
* Some material in this article was derived from the unpublished lectures of the author: The Microchemical Trend in Analytical Biochemistry (A Tribute to Oscar Bodansky, Memorial Sloan-Kettering Cancer Center, New York City, May 23, 1978), Development of Microanalytical Biochemistry - Some General Reflections (The Gerald T. Evans Lecture, Department of Laboratory Medicine and Pathology, University of Minnesota, Minneapolis, September 25, 1981)
} 
and refined them and developed new ones as new principles were applied, have been given repeatedly (e.g., 7).

The progression of the microchemical technology following titrimetry, gasometry, spectrophotometry, microbiological assay, fluorometry, radiometric and immunological methods, and luminometry, each with its own limitations and special advantages as the development advanced, brought the quantitative capability from the microgram to the femtogram range of sensitivity, and in some cases even beyond (8). Many practical applications followed, such as the prenatal screening of cells for inherited enzyme deficiencies (5), etc., etc.

A parallel progression occurred from the use of direct physical techniques. One of the most important of these was microspectrophotometry, pioneered by CASPERSSON (2), and used by his group and others for the ultraviolet and visible absorption measurement of unstained and stained substances and enzymatic products in cell structures, a technique which rapidly gained notice. Attention was drawn to early practices in the sample preparation and measurement which resulted in errors (6), but this was followed by development of means of overcoming certain serious errors, such as that due to inhomogeneity of the field of measurement - the "distribution error" $(11,12)$.

The extention of the absorption measurements to those of microspectrofluorometry opened additional avenues, and a discussion of the trends in quantitative histochemistry dealing mainly with both of these techniques was given recently by STOWARD (14). These two approaches and also light-scattering measurements have been exploited in the flow cytometry technique applied to single cells and cellular particulates in suspension (10). All of these techniques are being used increasingly with immunological markers, which were originated and summarized earlier by COONS (4) and then developed particularly by NAKANE, STERNBERGER and others, see STERNBERGER (13).

Prominent among techniques used in conJunction with, or independently of, the immunological ones, have been various forms of chromatography and electrophoresis. Interest in two-dimensional electrophoresis was stimulated by the work of N.G. ANDERSON and colleagues, as evidenced by an entire issue of the journal, Clinical Chemistry, being devoted to the subject (3). Also, quantitative autoradiography, X-ray, ultraviolet and visible emission spectroscopy, mass spectrometry, X-ray absorption, interference microscopy and quantitative electron microscopy, all have been applied (refs. in 8).

Aside from the experimental means available as mentioned before, another factor that has become increasingly limiting to progress in this, as in other fields of science, is the influence of predetermined policies of supporting agencies. This can have the unfortunate consequence of stifling creativity when, for example, research support is focused on assured results of shorter term projects, rather than on the more imaginative continuing programs without the lure of immediate "pay-off". While such control of support and directed research may be appropriate in some applied fields, it is fraught with danger for pure research. This is not to say that important advances cannot be stimulated by the directed research, though this channeling of effort diverts activity from other areas which may or may not yield benefits as great or greater. But the greatest danger of the channeling lies in inhibiting most the most creative.

Then there is the trend in research which can result in scientific advances proceeding in fits and starts dictated by fashion, sometimes initiated or accelerated by new instruments or technology. When in 1934 ROBERT R. BENSLEY and NORMAN L. HOERR at the University of Chicago first published the centrifugal isolation of liver mitochondria (1), they promoted a flood of investigation of these and other easily-obtainable subcellular particulates that was unusually popular for some years. I remember a remark by a university professor who said at the time that a prominent journal in biochemistry had almost become a "Journal of Mitochondria".

Fashions in science, as in other human activities, can arise from the same kind of human incentives, the excitement of joining the surge to be in the current movement with possibilities of prestige and financial advantage, to identify with peer groups, etc. As in the case of research directed by the control of support, it cannot be denied that important advances have also resul- 
ted from exploiting fashionable areas in science, though here too the diversion of effort from other areas which may or may not have conferred benefits as great or greater is not certain. But for better or worse, fashion is a human condition to be reckoned with. It can only be hoped that its uncritical acceptance will be shunned.

To return to the study of cells and their component structures, they and all other organized systems including tissues, organs, individuals and societies, are subject to a universal rule that functions in their regulation and adaptation - a rule that also operates in physical systems. That is, when some form of stress is applied to any dynamic system, the system reacts to relieve the stress by a shift in the balance of opposing tendencies. This has been defined in chemistry as Le Chatelier's principle, and in biology and medicine it is known as homeostasis. Economists, political scientists and sociologists must have their own terms for the phenomena, but in all cases the integrated functions of the units of each of these organized bodies makes each one of them an organism. LEWIS THOMAS illustrated the point in his essays, On Societies as Organisms, and Organelles as Organisms (15). The point had also been made by OTTO LOEWI, Nobel LaUREATE, 1936. In an address at the University of Virginia Medical School in May 1948, which was never published as far as I know, he cited experiments illustrating adaptation and regulation in the organisms, the bee and bee hive.

Normally, newly produced bees start out as nursing bees with growth of their salivary glands from feeding the larvae in the hive with honey, and the pollen brought by collector bees whose salivary glands are atrophied. Later, the nursing bees become architect bees for the comb production by transformation of their salivary to wax glands. Finally, the architects become collector bees with atrophy of the wax glands. However, if the collector bees are removed from the hive, the nursing bees become collectors with atrophy of their salivary glands. But if the nursing bees are removed from the hive, the collectors regenerate their salivary glands and become nursing bees.

The response of the bee to needs of the hive is not unlike the response of the units and subunits of living matter to the needs of the bodies in which they exist, and the understanding of the role of these units and subunits brings us back to histo- and cytochemistry.

To conclude, it is apparent that to approach the goal of quantitative histo- and cytochemistry, as stated at the outset, will require the continuing development of the recognition and measurement of chemical localizations in the ultimate structures of living matter. In our own lifetime we have seen many avenues of advance accelerating toward the goal, and we cannot even surmise what new paths the progress will open. But of what we can be certain is that, as applications are made of these advances, humankind will continue to benefit significantly, and that the influence will never cease of those who, like HEINZ HOL TER, have made important contributions to the basis of these advances.

On a more personal level, I have tried to crystallize something of what I know to be true of HEINZ, my good friend for over 50 years for whom I have always had great respect as a scientist and particular admiration as a person:

Too wise to be moved by trappings of fame,

Too clear in perception, too great in humor to take too seriously, himself or those who do,

He hews to the essence with perspective unclouded.

He is great as the truly civilized are great.

And those who have known the depth of his understanding and the sunlight of his warmth will always retain an abiding respect and deep affection for him that will continue to enrich their lives in as many ways as the many facets of this special man.

\section{REFERENCES}

1. BensLey, R.R. \& N.L. Hoerr: Studies on cell structure by the freezing-drying method. VI. The preparation and properties of mitochondria. Anat. Record 60, 449-455 (1934)

2. CASPERSSON, $T$.: Methods for the determination of the absorption spectra of cell structures. J.R. Microsc. Soc. 60, 8-25 (1940)

3. Clin. Chem. 28, No. 4, 737-1092 (1982) 
4. COONS. A.H.: Fluorescent antibody methods. In; General Cytochemical Methods, Vol. 1, (J.F. Danielli, ed.) Academic, New York, pp. 399-422 (1958)

5. Galgaard, H:: Genetic Metabolic Diseases. Early diagnosis and Prenatal Analysis, Elsevier, Amsterdam (1980)

6. Glick. D., A. Engstrom \& B.G. Malmstrom: A critical evaluation of quantitative histo- and cytochemical microscopic techniques. Science 114, 253-258 (1951)

7. Glick. D.: Quantitative Chemical Techniques of Histo- and Cytochemistry, Wiley-Interscience, New York, Vol. 1 (1961), Vol. 2 (1963)

8. GLICK. D: Trends in quantification in histochemistry and cytochemistry. Histochem. J. 13, 227-240 (1981)

9. Linderstrøm-Lang. K. \& H. Holter: Contributions to the histological chemistry of enzymes. $I$. The estimation of small cleavages caused by enzymes. Compt. Rend. Trav. Lab. Carlsberg, Sér.chim. 19, No. 4, 1-19; Z. physiol. Chem. 201, 9-30 (1931)
10. Melamed, M.R., P.F. Mullaney \& M.L. MenDELSOHN, EDS.: Flow Cytometry and Sorting. Wiley, New York (1979)

11. Mendelsohn. M.L.: Absorption cytophotometry: Comparative methodology for heterogeneous objects, and the two-wavelength method. In: Introduction to Quantitative Cytochemistry (G.L. Weid, ed.) Academic, New York, pp. 201-214 (1966)

12. ORnSteIn, L.: Distributional error in microspectrophotometry. Lab. Invest. 1, 250-265 (1952)

13. Sternberger, L.A.: Immunocytochemistry, 2nd edn. Wiley, New York (1979)

14. Stoward, P.J.: The past, present, and future of quantitative histochemistry. In: Histochemistry, The Widening Horizons of its Applications in the Biomedical Sciences (P.J. Stoward \& J.M. Polak, eds.) Wiley-Interscience, Chichester, pp. 263-280 (1981)

15. Thomas, L: The Lives of a Cell, Viking Press, New York, pp. 11-15, 69-74 (1974) 